\title{
Ética no relacionamento em saúde mental: análise fílmica a partir das histórias dos
}

\section{super-heróis}

\author{
Ethics in mental health relationships: film analysis based on the stories of superheroes \\ Ética en las relaciones de salud mental: análisis cinematográfico basado en las historias de
} superhéroes

Recebido: 27/12/2021 | Revisado: 02/01/2022 | Aceito: 08/01/2022 | Publicado: 11/01/2022

\author{
José Leandro Ramos de Lima \\ ORCID: https://orcid.org/0000-0001-9773-7049 \\ Universidade Federal de Alagoas, Brasil \\ E-mail: leandroramosdelima@hotmail.com \\ Marcos André dos Santos \\ ORCID: https://orcid.org/0000-0001-9832-9223 \\ Universidade Federal de Alagoas, Brasil \\ E-mail: andrcandido1@gmail.com \\ Isabel Comassetto \\ ORCID: https://orcid.org/0000-0002-2389-9384 \\ Universidade Federal de Alagoas, Brasil \\ E-mail: isabel.comassetto@eenf.ufal.br \\ Amuzza Aylla Pereira dos Santos \\ ORCID: https://orcid.org/0000-0001-6299-7190 \\ Universidade Federal de Alagoas, Brasil \\ E-mail: amuzza.pereira@eenf.ufal.br \\ Regina Santos \\ ORCID: https://orcid.org/0000-0002-2144-2997 \\ Universidade Federal de Alagoas, Brasil \\ E-mail: relpesantos@gmail.com \\ Maria Cicera dos Santos de Albuquerque \\ ORCID: https://orcid.org/0000-0002-5230-3447 \\ Universidade Federal de Alagoas, Brasil \\ E-mail: cicera.albuquerque@eenf.ufal.br
}

\begin{abstract}
Resumo
As relações sociais têm uma grande importância na saúde mental por serem influenciadoras na concepção desse cuidado. É provado historicamente a partir das civilizações o valor das relações humanas nas perspectivas do que é saúde e do que é doença. As condutas profissionais podem influenciar nas relações terapêuticas podendo ser um grande dificultador da promoção da saúde mental. Ao partir do viés ético, torna-se necessário o destaque da relação profissional-usuário por meio do acolhimento para construção da relação terapêutica. Objetivo: Este estudo teve como objetivo analisar, por meio do exercício da linguagem fílmica, os princípios éticos no relacionamento terapêutico entre profissionais de saúde e pessoas em sofrimento mental. Metodologia: Pesquisa do tipo qualitativa, exploratória com uso da estratégia de análise fílmica. Informações obtidas a partir da observação não participante e indireta, dos filmes: Vingadores: Era de Ultron, Doutor Estranho, Batman vs Superman: a origem da justiça, Coringa, Vidro e; a minissérie: WandaVision. Resultados: A partir da análise do material, as informações foram organizadas nas categorias: O profissional reconhecendo limites e limitações; Compreender as dimensões do usuário; Potencializar os recursos do usuário; Lidar e respeitar as limitações do usuário; Relações de poder. Conclusão: Observa-se a partir de tramas baseadas em histórias de super heróis, a importância e, ao mesmo tempo, a complexidade do processo de cuidar em saúde mental; e os aspectos éticos que resultam na promoção da saúde mental e dependem das condutas dos profissionais que atuam na atenção psicossocial.
\end{abstract}

Palavras-chave: Saúde mental; Ética; Relações enfermeiro-paciente; Relações interpessoais.

\begin{abstract}
Social relationships are of great importance in mental health as they influence the design of this care. The value of human relationships from the perspectives of what is health and what is disease is historically proven from civilizations. Professional behaviors can influence therapeutic relationships and can be a major hindrance to the promotion of mental health. Based on the ethical bias, it is necessary to highlight the professional-user relationship through embracement for the construction of the therapeutic relationship. Objective: This study aimed to analyze, through the exercise of film language, the ethical principles in the therapeutic relationship between health
\end{abstract}


professionals and people in mental suffering. Methodology: Qualitative, exploratory research using the film analysis strategy. Information obtained from non-participant and indirect observation of the films: Avengers: Age of Ultron, Doctor Strange, Batman vs Superman: The Origin of Justice, Joker, Glass and; the miniseries: WandaVision. Results: From the analysis of the material, the information was organized into categories: The professional recognizing limits and limitations; Understand the dimensions of the user; Leverage user resources; Deal with and respect user limitations; Power relations. Conclusion: Based on plots based on stories of super heroes, the importance and, at the same time, the complexity of the mental health care process can be observed; and the ethical aspects that result in the promotion of mental health and depend on the behavior of professionals who work in psychosocial care.

Keywords: Mental health; Ethics; Nurse-patient relations; Interpersonal relations.

\section{Resumen}

Las relaciones sociales son de gran importancia en la salud mental ya que influyen en el diseño de esta atención. El valor de las relaciones humanas desde las perspectivas de lo que es salud y lo que es enfermedad está probado históricamente por las civilizaciones. Los comportamientos profesionales pueden influir en las relaciones terapéuticas y pueden ser un obstáculo importante para la promoción de la salud mental. Partiendo del sesgo ético, es necesario resaltar la relación profesional-usuario a través de la acogida para construir la relación terapéutica. Objetivo: Este estudio tuvo como objetivo analizar, a través del ejercicio del lenguaje cinematográfico, los principios éticos en la relación terapéutica entre los profesionales de la salud y las personas en sufrimiento mental. Metodología: Investigación exploratoria cualitativa utilizando la estrategia de análisis cinematográfico. Información obtenida de la observación indirecta y no participante de las películas: Avengers: Age of Ultron, Doctor Strange, Batman vs Superman: El origen de la justicia, Joker, Glass y; la miniserie: WandaVision. Resultados: A partir del análisis del material, la información se organizó en categorías: El profesional reconociendo límites y limitaciones; Comprender las dimensiones del usuario; Aprovechar los recursos de los usuarios; Tratar y respetar las limitaciones del usuario; Relaciones de poder. Conclusión: A partir de tramas basadas en historias de superhéroes, se puede observar la importancia y, al mismo tiempo, la complejidad del proceso de atención a la salud mental; y los aspectos éticos que redundan en la promoción de la salud mental y dependen del comportamiento de los profesionales que laboran en la atención psicosocial.

Palabras clave: Salud mental; Ética; Relaciones enfermero-paciente; Relaciones interpersonales.

\section{Introdução}

As modificações das relações sociais e dos paradigmas da prática de saúde, ao longo da história, apresentam influência quanto às concepções acerca da saúde mental (Gaino et al., 2018), bem como ao considerar o relacionamento entre profissional e a pessoa em sofrimento psíquico. Tal variação é compreendida principalmente a partir do entendimento sobre a loucura, a qual, teve a sua natureza representada de formas diferentes a cada formatação da sociedade (Batista, 2018).

$\mathrm{Na}$ antiguidade e na idade média, por exemplo, a loucura era representada de forma mística. Na antiga sociedade grega, a valorização de pessoas com comportamentos diferentes se dava pela crença de que elas representavam o vínculo entre o mundo dos mortais e as divindades. Na idade média, por sua vez, diante dos dogmas da igreja cristã, acreditava-se que a pessoa acometida pela loucura estava enfrentando algum tipo de punição divina. Com o passar do tempo e a queda do poderio religioso, essas pessoas passaram a ser retiradas do convívio social (Batista, 2018).

Foi nessa perspectiva que o modelo manicomial surgiu e se estabeleceu. Uma vez que se classificou a loucura enquanto doença, o internamento em asilos foi visto como a principal proposta de tratamento, uma vez que se compreendia que a loucura necessitava ser curada. Ressalta-se que os manicômios eram espaços de segregação não apenas para as pessoas com acometimento por algum transtorno mental, mas, igualmente destinados a todos aqueles que eram julgados pela sociedade como indesejáveis e que necessitasse de algum tipo de correção de conduta (Scudeler, 2020; Batista, 2018).

Os asilos, por anos, foram instituições dominadas pela medicina e pelo poder religioso, os quais submetiam aqueles que eram ditos loucos, a situações de violência, tortura e punição com o intuito de promover controle social, moral e corretivo, diante de todo comportamento que fugisse à compreensão de normalidade. Foram anos de promoção de ameaças, privações e humilhações, às quais a medicina esteve à frente não por estabelecer competência científica, na época, mas para manter relação de domínio sobre os corpos (Scudeler, 2020). 
Portanto, os asilos e hospícios se configuram como instituições onde a psiquiatria se apropriou do saber sobre a loucura, onde realiza jogo de poder de forma opressora sobre as pessoas que adentram às suas portas, independente se os procedimentos lá realizados receberam uma nova roupagem humanizada ou não. Apenas no período pós guerra, com advento de novas tecnologias para tratamento dos transtornos mentais, que ocorreram os primeiros movimentos para a reforma psiquiátrica. Na década de 1960 o psiquiatra Franco Basaglia propôs a reformulação da prática diante da loucura, ao compreendê-la numa ótica de inclusão social e garantia de direitos (Scudeler, 2020; Gaino et al., 2018).

Foi nessa perspectiva em que a reforma psiquiátrica brasileira se alicerçou, propondo o redirecionamento do lócus onde se promove saúde mental. Muito mais que uma prática que considera o ambiente em que o cuidado ocorre, mas seguindo conceitos que norteiam a práxis em saúde mental. Por anos, os investimentos voltados para os hospitais psiquiátricos foram transferidos para criação, ampliação e fortalecimento de serviços substitutivos, no Brasil. Entretanto, em 2017, a proposta hospitalocêntrica voltou a ganhar forças, mediante a inclusão dos serviços hospitalares psiquiátricos à Rede de Atenção Psicossocial (RAPS) (Sousa \& Jorge, 2019; Almeida, 2019).

Portanto, ainda hoje, a sociedade vivencia duas lógicas de propostas de cuidado em saúde mental. O primeiro sendo o paradigma biomédico, o qual tem por foco a doença e suas manifestações, bem como seu controle por meio da medicalização. Aqui, a loucura é o objeto de estudo da psiquiatria. Já o segundo, é o paradigma proposto pela reforma psiquiátrica, o qual propõe a reprodução social de saúde, em que as pessoas podem conviver com os transtornos mentais e possuir qualidade de vida, trabalhar, desenvolver suas habilidades, potencialidades e conviver em comunidade (Gaino et al., 2018).

Independente do paradigma e do serviço o qual a pessoa busca atendimento, faz-se necessário compreendê-la quanto a dignidade que the é garantida, conforme a Lei $\mathrm{n}^{\circ}$ 10.216/2001 que dispõe da proteção e direitos das pessoas com transtorno mental. Portanto, cabe ao profissional garantir proteção da vida, da integridade física e psíquica, da liberdade e da personalidade da pessoa com transtorno mental. Sendo a dignidade o guia condutor desse encontro entre pessoa e profissional de saúde (Mendonça, 2019).

Entretanto, entre os fatores de vulnerabilidade que mais se destacam no âmbito do relacionamento terapêutico, é possível apontar aquele que se refere à autonomia. Uma vez que alguns transtornos mentais podem promover ruptura (em diversos níveis) entre a pessoa e a compreensão do mundo a sua volta. O que pode afetar nas condições para tomada de decisões, dentre elas a de escolha sobre qual tipo de tratamento a pessoa gostaria de definir para atender às suas necessidades. O que acaba por submetê-la a decisões tomadas por terceiros, sejam eles familiares ou o próprio profissional de saúde mental (Mendonça, 2019).

Em tais situações, cabe cautela por parte do profissional, uma vez que o mesmo irá interferir no percurso de vida e em questões sensíveis que podem ser irreparáveis após sua decisão de intervenção/conduta. Diante disso, é propícia a relação entre linguagem fílmica e fenômenos vivenciados, observados ou estudados no cotidiano onde os profissionais e indivíduos/familiares comunicam-se entre si.

No meio científico, no ano de 1916, Hugo Munsterberg estudou a relação cinema e psicologia, abordando sobre como a percepção do cinema levava o telespectador a ter uma recriação mental (Munsterberg, 2003). Nessa conjuntura, Viegas (2008) relata que o olhar, a percepção e a memória são agentes modificadores do real e irreal, tornando os telespectadores mais do que receptores, pois, realizam trabalho intelectual fazendo uma reflexão sobre o real e irreal.

Portanto, tendo em vista, os impactos que a relação entre profissional de saúde mental e usuário do serviço podem causar, principalmente mediante a perspectiva da autonomia da pessoa em sofrimento mental, e o desejo em utilizar a linguagem fílmica em pesquisa científica, elaborou-se a seguinte questão norteadora: De que modo o exercício da linguagem fílmica, pode ser utilizado para análise dos princípios éticos no relacionamento terapêutico entre profissionais de saúde e 
pessoas em sofrimento mental? O principal objetivo é analisar, por meio do exercício da linguagem fílmica, os princípios éticos no relacionamento terapêutico entre profissionais de saúde e pessoas em sofrimento mental.

Para tanto, esta análise irá partir de elementos contidos em filmes de super-heróis, tendo em vista a influência desta cultura na sociedade contemporânea, bem como a riqueza de conceitos éticos, morais e de outras questões pertinentes à formação humana, contidas nessas estórias e contos (Fuentes, 2017).

\section{Metodologia}

Pesquisa do tipo qualitativa, exploratória com uso da estratégia de análise fílmica, a partir das informações produzidas por meio da observação não participante e indireta, a qual se caracteriza como observação realizada por meio do uso de fotografias, vídeos ou filmes através de análise fílmica de conteúdo (Barin et al, 2020; Freitas \& Leite, 2015; Machado et al., 2012; Flick, 2009).

A análise fílmica defendida por Flick (2009), tem por definição uma estratégia em que o observador não influencia o evento ou fenômeno observado, uma vez que o próprio observador interpreta os resultados e constrói os significados. Desenvolve pressuposições e direciona a ação dos atores da forma como o próprio as percebe. É compreendida como estratégia menos tendenciosa, uma vez que o acesso às informações por meio das cenas ocorre de forma facilitada, podendo os registros serem avaliados tantas vezes quanto forem necessários. Tal método permite a inclusão de vários aspectos diferentes a partir de um mesmo fato (Freitas \& Leite, 2015; Leite et al., 2010).

Segundo Vanoye e Goliot-Lété (2006), a análise fílmica é seguida de etapas principais como: a decomposição das cenas em planos e a análise do que essa decomposição causa nesses elementos decompostos. De acordo com Penafria (2009), a análise possui tipos de análise técnicas que se classificam em: análise textual, análise de conteúdo, análise poética e análise imagem e som.

Para esta análise fílmica foi utilizado o protocolo proposto por Machado, Matos, Leite e Leite (2012), obedecendo as seguintes etapas: 1) construção da questão ou objetivo de pesquisa; 2) busca e seleção da fonte de dados narrativos; 3) visão geral da narrativa fílmica; 4) decupagem dos dados (cenas e falas); 5) fundamentação e interpretação teórica dos dados e; 6) produção do relatório final, conforme é ilustrado na Figura 1. Foram definidos como critérios para a seleção dos filmes, uso dos filmes de super heróis para compreender a relação entre profissional de saúde e pessoa com transtorno mental, o fato dos filmes de super heróis serem pautados em temáticas éticas e morais aplicáveis à realidade, possibilidade de trabalhar um discurso, a partir da análise de discurso e possibilidade de realizar simulações a partir da fantasia.

Figura 1: Etapas para análise fílmica, segundo protocolo de Machado, et al. (2012).

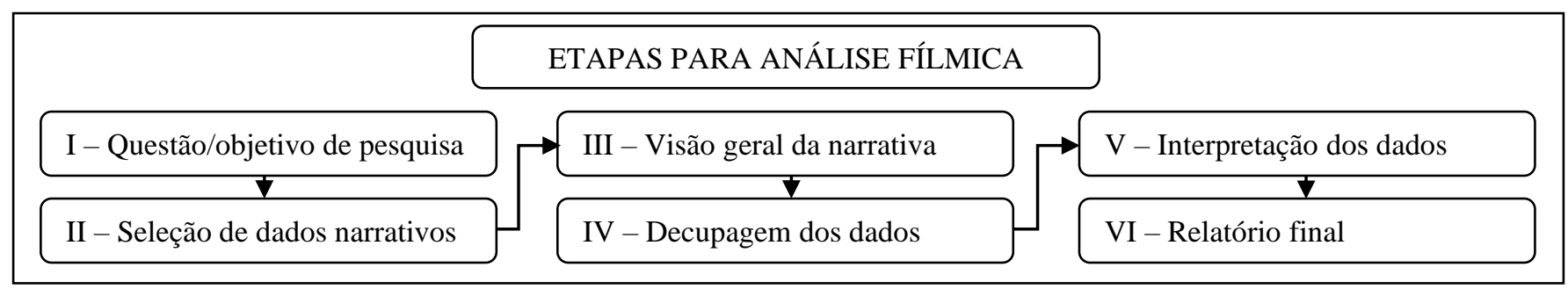

Fonte: Machado, et al. (2012).

Sendo assim, foram analisados os enredos dos filmes: Vingadores: Era de Ultron (Whedon, 2015), Doutor Estranho (Derrickson, 2016), Batman vs Superman: a origem da justiça (Snyder, 2016), Coringa (Phillips, 2019), Vidro (Shyamalan, 2019); e a minissérie: WandaVision (Shakman, 2021). Para realizar a análise dos dados, foram utilizadas referências da 
literatura para encorpar o observado nas cenas e falas, auxiliar na interpretação e orientar a análise reflexiva realizada por este estudo.

\section{Resultados}

Aqui, apresenta-se os dados levantados a partir da análise das cinco fontes utilizadas, as quais seguem os enredos de cada uma delas (Quadro 1).

Quadro 1: Enredo dos filmes e minissérie utilizados como fonte de coleta de dados, em 2021.

\begin{tabular}{|c|c|c|}
\hline TÍTULO & DIREÇÃO, ANO & ENREDO \\
\hline $\begin{array}{l}\text { Vingadores: Era } \\
\text { de Ultron }\end{array}$ & Joss Whedon, 2015 & $\begin{array}{l}\text { Os Vingadores invadem um posto da Hidra em Sokovia, onde testes estavam sendo realizados em humanos com } \\
\text { o cetro uma vez utilizado por Loki. Durante a investida, encontram dois dos experimentos, os irmãos Masximoff, } \\
\text { Pietro, dotado de super-velocidade, e Wanda que domina a telecinesia. O Homem de Ferro recupera o cetro e, } \\
\text { junto ao Bruce Banner (Hulk), descobrem uma inteligência artificial dentro da gema do cetro. Utilizam-na para } \\
\text { construir um programa de defesa global, chamado de Ultron, mas que acaba se virando contra os Vingadores e a } \\
\text { humanidade. Ultron utiliza Wanda e Pietro para retardar as investidas dos heróis enquanto tenta concluir seus } \\
\text { planos de proteção global: exterminar toda vida humana. }\end{array}$ \\
\hline Doutor Estranho & $\begin{array}{l}\text { Scott Derrickson, } \\
2016\end{array}$ & $\begin{array}{l}\text { Stephen Strange é um neurocirurgião renomado e arrogante que, após a perda dos movimentos das mãos em um } \\
\text { acidente, tenta de diversas formas se recuperar dos ferimentos e limitações que o impedem de retomar sua rotina } \\
\text { de trabalho. Após utilizar todos os recursos e perder o apoio de sua colega e amante Christine Palmer, Strange } \\
\text { ouve falar de métodos utilizados no Nepal que podem ajudá-lo. Nessa busca, conhece um clã de feiticeiros que } \\
\text { irão auxiliar em uma jornada de superação para além das limitações físicas. Enquanto isso, ex-discípulos } \\
\text { corrompidos tentam invocar a dimensão negra e utilizar o poder de Dormammu para impedir que o tempo passe } \\
\text { e possam viver para sempre. }\end{array}$ \\
\hline $\begin{array}{l}\text { Batman vs } \\
\text { Superman: a } \\
\text { origem da justiça }\end{array}$ & Zack Snyder, 2016 & $\begin{array}{l}\text { Após a destrutiva batalha entre Superman e o invasor kryptoniano General Zod, faz com que a população } \\
\text { enxergue o herói de forma controversa. Bruce Wayne culpa Superman pelas mortes causadas na batalha, } \\
\text { enquanto que Clark Kent tenta expor o vigilante de Gotham City. O magnata Lex Luthor tenta de todas as formas } \\
\text { garantir que seu projeto de armas biológicas utilizando kriptonita seja aprovado para derrotar de uma vez por } \\
\text { todas o herói kryptoniano. }\end{array}$ \\
\hline Coringa & Todd Phillips, 2019 & $\begin{array}{l}\text { O filme retrata a origem do arquiinimigo do Batman, o Coringa. Em 1981, Arthur Fleck trabalha como palhaço } \\
\text { nas ruas de Gotham City, uma cidade marcada pelas diferenças sociais e pela violência. Arthur convive com um } \\
\text { transtorno neurológico que o faz rir nas situações mais inoportunas, além de enfrentar sofrimento psíquico } \\
\text { significativo. É usuário do serviço de assistência social pública de onde retira as medicações que faz uso diário. } \\
\text { Tem sonho de se tornar comediante, mas seu passado e presente o levarão a caminhos muito mais obscuros. }\end{array}$ \\
\hline Vidro & $\begin{array}{c}\text { Manoj Nelliattu } \\
\text { Shyamalan, } 2019\end{array}$ & $\begin{array}{l}\text { Kevin Crumb, David Dunn e Elijah Price são levados para participar de uma pesquisa em um hospital } \\
\text { psiquiátrico que será concluída em três dias, a qual tem a intenção de convencê-los de que não são dotados de } \\
\text { super poderes, evidenciando que na verdade são sensíveis a sugestionabilidade. Enquanto isso, amigos e } \\
\text { familiares de cada um tentam encontrar formas de ajudá-los a sair da instituição onde foram internados. }\end{array}$ \\
\hline WandaVision & Matt Shakman, 2021 & $\begin{array}{l}\text { Após a invasão de Thanos em busca das jóias do infinito, Wanda e Visão buscam se refugiar na pacata cidade de } \\
\text { Westview, onde tentam esconder suas reais identidades. Entretanto, a rotina da cidade é transformada ao } \\
\text { vivenciar a realidade de sitcoms de diferentes décadas, evidenciando que algo ou alguém os está controlando. }\end{array}$ \\
\hline
\end{tabular}

Fonte: Dados da pesquisa.

A partir dos registros das cenas e falas foi possível categorizar o contexto e fragmentos extraídos conforme a seguir: $\mathrm{O}$ profissional reconhecendo limites e limitações; Compreender as dimensões do usuário; Potencializar os recursos do usuário; Lidar e respeitar as limitações do usuário; Relações de poder (Quadro 2). Ressalta-se que as falas e cenas não estão transcritos na íntegra. Os dados levantados serão interpretados de acordo com a característica do contexto aqui proposto. 
Quadro 2: Categorização dos contextos e fragmentos extraídos dos filmes e minissérie utilizados como fonte de coleta de dados, em 2021.

\begin{tabular}{|c|c|}
\hline CATEGORIA & CONTEXTOS E FRAGMENTOS EXTRAÍDOS \\
\hline $\begin{array}{l}\text { O profissional } \\
\text { reconhecendo } \\
\text { limites e } \\
\text { limitações }\end{array}$ & $\begin{array}{l}\text { 1) Dirigindo em alta velocidade, Strange se envolve em um acidente de carro, uma vez que não é capaz de prever as condições e obstáculos } \\
\text { presentes na estrada, como chuva e outros carros pelo caminho (Doutor Estranho); } \\
\text { 2) Os relacionamentos de Strange se baseiam em suas conquistas profissionais. Sem ter como exercer sua profissão diante da limitação das } \\
\text { mãos machucadas, sente-se inutilizado: "não há vida sem meu trabalho" (Doutor Estranho); } \\
\text { 3) Anciã: "O medo de falhar o fez ser um bom médico, mas a arrogância o impediu de perceber que não era sobre você" (Doutor Estranho); } \\
\text { 4) No primeiro encontro entre Stephen Strange e a Anciã, o mesmo pergunta qual método ela utilizou para que um homem tetraplé gico } \\
\text { retornasse a andar. A mesma responde que assim como as células são programadas para reconstruir tecido de formas específicas, o corpo } \\
\text { pode ser convencido a se recuperar de várias formas (Doutor Estranho); } \\
\text { 5) Apegado ao conhecimento biologicista, questiona se a Anciã utiliza tecnologia de regeneração celular, a mesma responde que trabalha } \\
\text { com a reconstrução do espírito para a cura do corpo (Doutor Estranho); } \\
\text { 6) Strange aprende a lição de que nem tudo precisa ou terá sentido. É necessário silenciar o ego para que o poder surja (Doutor Estranho); } \\
\text { 7) Diante da bomba detonada durante o julgamento, Clark sente-se desapontado "Não vi a bomba porque não estava olhando" (Batman vs } \\
\text { Superman: a origem da justiça); }\end{array}$ \\
\hline $\begin{array}{c}\text { Compreendendo } \\
\text { as dimensões do } \\
\text { usuário }\end{array}$ & $\begin{array}{l}\text { 1) Wanda Maximoff tem habilidade para controle da mente de seus adversários, manipulando o pensamento e a realidade deles. Apresenta- } \\
\text { se como inimiga dos Vingadores, devido a traumas vivenciados no passado. Até perceber que, assim como eles, também pretende proteger o } \\
\text { mundo contra a ameaça de Ultron (Vingadores: Era de Ultron); } \\
\text { 2) Wanda apresenta dificuldade em lidar com o luto. Então, utiliza de seus poderes para manipular as pessoas e criar uma realidade } \\
\text { alternativa, onde se sente protegida e amada. Fugindo da realidade que lhe causa sofrimento, toda pessoa que tenta trazê-la para a realidade é } \\
\text { banida pela barreira de magia que separa ela e toda cidade de Westview, do resto do mundo (WandaVision). } \\
\text { 3) Durante os atendimentos com a profissional de assistência social, Arthur expressa estar desacreditado com o rumo que a vida toma "só } \\
\text { espero que a minha morte faça mais sentido que a minha vida". Ao ser questionado como se sente nas consultas e sobre ter alguém que o } \\
\text { escuta, o mesmo responde que sentia-se melhor quando estava no sanatório. Em outro momento, Arthur deixa claro que sente que não é } \\
\text { ouvido pela profissional, que as perguntas se repetem toda semana e quando ela pergunta se o mesmo tem apresentado pensamentos } \\
\text { negativos, responde "tudo o que tenho são pensamentos negativos" (Coringa); } \\
\text { 4) O riso incontrolado de Arthur se faz presente em momentos desconfortáveis, inclusive em situações em que o mesmo tem desconforto ou } \\
\text { dor corporal, bem como tristeza. Na infância, Arthur sofreu com situações de violência doméstica, mas a mãe sempre se referiu a ele como } \\
\text { uma criança feliz e o apelidava de "Feliz" (Coringa). }\end{array}$ \\
\hline $\begin{array}{l}\text { Potencializar os } \\
\text { recursos do } \\
\text { usuário }\end{array}$ & $\begin{array}{l}\text { 1) A Anciã explica para Strange que o corpo representado por imagens de exames ou a partir da medicina oriental são apenas partes do todo. } \\
\text { Pede para que Strange "Abra seu olho", afirma que "pensamentos moldam a realidade (...) na origem da existência, mente e matéria se } \\
\text { encontram (...) alguns universos são propensos à vida, outros são cheios de fome e maldade (...) quem é você nesse vasto multiverso, } \\
\text { Strange?" (Doutor Estranho); } \\
\text { 2) Strange aprende que a magia vem da conexão da energia do multiverso para criar escudos ou armas (Doutor Estranho); } \\
\text { 3) Kevin não se sentia bem em permanecer na luz, o que deu evidência às outras personalidades da Horda. Em seus momentos finais de } \\
\text { vida, ao estar acompanhado de uma pessoa querida, Kevin sentiu-se fortalecido para permanecer na luz (Vidro). }\end{array}$ \\
\hline $\begin{array}{c}\text { Lidar e respeitar } \\
\text { as limitações do } \\
\text { usuário }\end{array}$ & $\begin{array}{l}\text { 1) Anciã: "Nós nunca perdemos nossos demônios, apenas aprendemos a viver com eles" (Doutor Estranho); } \\
\text { 2) Anciã: "você não pode domar o rio, é preciso se render à corrente e usar o poder dele como se fosse seu" (Doutor Estranho); } \\
\text { 3) Strange é alertado quanto ao uso do Olho de Agamotto, o mesmo deve ser protegido e não manipulado (Doutor Estranho); } \\
\text { 4) Ao perceber o poder de Dormammu, Strange se sacrifica a morrer várias vezes num loop infinito no tempo como única forma de } \\
\text { enfrentar o poderoso inimigo (Doutor Estranho); }\end{array}$ \\
\hline $\begin{array}{l}\text { Consequências do } \\
\text { encontro entre } \\
\text { profissional e } \\
\text { usuário }\end{array}$ & $\begin{array}{l}\text { 1) O ataque avassalador de General Zod e a batalha com o Superman causam destruição e morte de inocentes (Batman vs Superman: a } \\
\text { origem da justiça); } \\
\text { 2) A sociedade amedrontada diante do poder do Superman "o mundo ficou tão maravilhado com as coisas que o Superman conseguia fazer } \\
\text { que ninguém se perguntou quais ele deveria fazer" (Batman vs Superman: a origem da justiça); } \\
\text { 3) O julgamento do Superman diante das consequências que seus atos causaram à população (Batman vs Superman: a origem da justiça); } \\
\text { 4) Revisitando memórias do pai terrestre, Clark relembra de uma enchente que afetou a fazenda da família, para salvá-la e aos animais, ele e } \\
\text { o pai redirecionaram o curso da água da chuva. Assim, a água seguiu para a fazenda vizinha. Clark recorda que enquanto dormia, podia } \\
\text { ouvir o barulho que os animais faziam enquanto se afogavam. Evidenciando que toda boa ação tem uma consequência (Batman vs } \\
\text { Superman: a origem da justiça). }\end{array}$ \\
\hline $\begin{array}{c}\text { Relações de } \\
\text { Poder }\end{array}$ & $\begin{array}{l}\text { 1) O uso do conhecimento para ter controle das relações entre os colegas de trabalho, ao acreditar que ninguém é tão competente quanto ele, } \\
\text { e diante das relações pessoais (Doutor Estranho). } \\
\text { 2) A Anciã ensinou a Strange que não se deve acessar os poderes de Dormammu, mas a mesma o fez por julgar necessário "em nome de um } \\
\text { bem maior" (Doutor Estranho); } \\
\text { 3) Na sala de atendimento, Arthur e a profissional têm seus espaços bem definidos. A profissional por trás de uma mesa, com o olhar } \\
\text { direcionado às suas anotações. Enquanto Arthur apresenta-se desconfortável em estar naquele espaço (Coringa); } \\
\text { 4) A médica Ellie Staple, junto com sua equipe, retira sujeitos do convívio social para o interior de um hospital psiquiátrico sob a premissa } \\
\text { de conduzir uma pesquisa em três dias a qual convencerá pessoas com suposto transtorno de grandeza de que não são super heróis (Vidro); } \\
\text { 5) A médica acredita que a crença em ser super heróis se relaciona à traumas vivenciados em algum ponto da infância (Vidro); } \\
\text { 6) Ao avaliar os exames de imagem de um dos pacientes, a médica Ellie julga pela semelhança dos casos que os outros dois apresentam } \\
\text { danos semelhantes, dispensando submetê-los sobre as mesmas condições de avaliação (Vidro). } \\
\text { 7) A sociedade secreta a qual Ellie faz parte, busca manter o equilíbrio da sociedade, evitando que super heróis e super vilões se } \\
\text { desenvolvam (Vidro). }\end{array}$ \\
\hline
\end{tabular}

Fonte: Dados da pesquisa. 


\section{Discussão}

Os destaques realizados a partir dos materiais acessados, quando observados na perspectiva da conduta ética do profissional de saúde, diante da pessoa em sofrimento mental, fazem emergir conteúdos que se relacionam, primeiramente, na compreensão dos limites de atuação diante de outra vida. Assim como das limitações do profissional que, antes de tudo, também é humano e inspira cuidados.

O entendimento de limites, por parte do profissional, apresenta relação na forma como o mesmo compreende as suas ações no sentido de promover cuidado. Este, por sua vez, pode assumir direções distintas, de acordo com a visão de mundo deste profissional. Pode ter direcionamento no aspecto técnico, o qual é exclusivamente instrumental, intervencionista, tende a desconsiderar as particularidades e a objetificar a pessoa que busca cuidado. Trata-se de uma lógica reducionista, a qual compreende o indivíduo, apenas como o procedimento o qual será realizado (Araújo \& Bassalo, 2019). É sob essa lógica que se ancora a arrogância do Doutor Estranho observada no filme e evidenciada na fala da Anciã, o que o impede de perceber que o ato de cuidar vai além da excelência da prática profissional, que o verdadeiro foco é a pessoa que está diante dele.

Sendo assim, a lógica oposta ao cuidado tecnicista, o compreende como parte íntima da constituição do ser humano. Valoriza a experiência de vida, a qual oportuniza à pessoa a possibilidade de mudança, de transformação e de preocupar-se com tudo o que a rodeia (Araújo \& Bassalo, 2019). Portanto, pode-se dizer que o profissional ao executar ato de cuidar, nesse aspecto, o realiza centrado nas necessidades do usuário do serviço, compreendendo-se como instrumento de promoção de saúde.

De forma semelhante, observa-se a lógica de atuação em saúde mental, uma sob a ótica biologicista e medicalocêntrica, a qual se associa ao modelo manicomial, o qual se afasta da atenção humanizada compreendendo as particularidades do usuário. E realizando o contraponto, o modelo biopsicossocial, o qual se ampara a Reforma Psiquiátrica brasileira e propõe um modelo de atenção considerando todos os fatores de vulnerabilidade que podem causar desequilíbrio no processo de saúde-doença em saúde mental (Peres, et al., 2018).

A pessoa que assume o papel de promover cuidado, pode ser levada a cair em algumas armadilhas para o ego. Por vezes, a sociedade tende a elevar os profissionais de saúde a posições sobre-humanas como a de "heróis da saúde" (Ferreira, 2020; Reis et al., 2018). Entretanto, diferente dos filmes, é preciso compreender que a condição de ser humano confere limitações. Assim como o Superman não foi capaz de detectar a presença da bomba na sala, o profissional de saúde não conseguirá atender, sozinho, a todas as demandas da pessoa diante dele.

Entretanto, ao entrar numa relação de cuidado em saúde mental, é preciso que o profissional se comprometa a investir nesse relacionamento. Para tanto, deve buscar compreender as dimensões que compreendem o usuário (Paula, 2008). Quando a análise faz um contraste do fictício com o humano no mundo real. Assim através da arte e da ficção através dos elementos envolvidos que no caso são os personagens, a atuação e o espaço de atuação para poder fazer a correlação com a realidade. Em Vingadores-Era de Ultron, Wanda Maximoff usa a sua habilidade adquirida de controle da mente, "aproveitando-se de uma técnica para fazer o mal", ou seja, utilizando um conhecimento aprendido com finalidades antiéticas a fim de desorganizar mentes alheias.

É possível apontar o aspecto antiético nesse sentido de conhecimento e se caracterizando em imprudência (Minossi, 2009). Trazendo esse contexto para o real é compreendido a partir de como se dar o processo de cuidado em saúde mental para aquela pessoa que vai em busca do cuidado em saúde mental devido o seu sofrimento e se encontra em situação vulnerável necessitando do apoio e cuidado do profissional da saúde mental qual possui habilidades quais podem acolher o seu sofrimento porém se o profissional vai por um percurso antiético como nas ficções as relações dos personagens como os apontados na 
Research, Society and Development, v. 11, n. 1, e45911125170, 2022

(CC BY 4.0) | ISSN 2525-3409 | DOI: http://dx.doi.org/10.33448/rsd-v11i1.25170

categoria esse acolhimento não se realiza como no caso do Coringa em que a profissional que atende o personagem nunca consegue acessar de fato a necessidade qual traz o sofrimento por um movimento negligente.

Uma vez inserido numa relação de cuidado junto ao usuário, o profissional deve ter em mente a busca em fortalecê-lo diante do seu contexto de vida. Ao considerar a pessoa como ser único, poderão ser propostas ações específicas às queixas e demandas apresentadas. Para tanto, pode-se lançar mão das conhecidas tecnologias leves, duras e/ou leve-dura. Considera-se tecnologia leve, aquelas que estão no campo do relacionamento interpessoal, entre profissional e usuário como o acolhimento e vínculo. As tecnologias duras, por sua vez, referem-se a todas que requerem o uso de equipamentos para prestação de assistência. Já a tecnologia leve-dura, refere-se à associação de conhecimentos, como epidemiologia e a clínica, para realizar o atendimento dentro da relação com o usuário. Na atenção psicossocial, portanto, o ato de cuidar deve estar centrado no respeito à subjetividade e a singularidade do usuário (Campos et al., 2018).

Ao associar os tipos de tecnologias de cuidado de forma individualizada, o profissional tende a não apenas potencializar as habilidades de quem recebe seus cuidados, mas promove proteção mediante situações que possam disparar desequilíbrio e crise diante do sofrimento psíquico. Pensamento que encontra associação na busca de Strange em utilizar a magia como fonte de recursos para se fortalecer.

$\mathrm{Na}$ atenção psicossocial é preciso garantir o espaço para que o usuário se expresse, para que possa experimentar a capacidade de pensar, de sentir e decidir sobre sua própria vida, para que possa exercer sua singularidade (Bossato et al., 2021). A exemplo de um dos recursos potentes para promoção de saúde mental, pode-se citar a aproximação da família e amigos como promotores de segurança no contexto de vida do usuário. É preciso garantir o fortalecimento dos laços familiares e da comunidade com esse usuário, dentro da perspectiva de vida que o compreende. Uma vez que o mesmo se sente seguro nos demais ambientes, além do serviço, o usuário tende a sentir-se confiante para se expressar quanto pessoa em todos os espaços que transita (Ferreira et al., 2019; Coelho et al., 2017). Assim como Kevin conseguiu assumir o controle de seu corpo ao estar acompanhado de uma pessoa querida.

Entretanto, não incomum, o transtorno mental também pode se configurar como um "fardo" para os familiares. Uma vez que, a depender do nível de comprometimento, leva a situações de dependência e necessidade de atenção integral (Ramos et al., 2019). O que pode levar a muitos cuidadores acreditarem estar se sacrificando em nome do transtorno que a pessoa vivencia, assim como Strange se colocou num loop infinito contra Dormammu. Nesse caso, observa-se a importância da percepção do profissional sobre todos os fatores de vulnerabilidade para usuário e familiares, para que possam ser reduzidos. A compreensão da família como parte fundamental do cuidado é estratégia para garantir que o usuário continue a se desenvolver quando pessoa dentro da comunidade em que vive (Ramos et al., 2019).

Assim como a Anciã ensina a Strange, é preciso compreender que nem sempre a cura será possível, mas a importância de conviver com as consequências que o transtorno mental traz para a vida de todos envolvidos. É preciso compreendê-lo para que, a partir desse conhecimento, traçar estratégias para que se obtenha o máximo de qualidade de vida.

A busca pelo cuidado em saúde mental pode partir de uma diversidade de necessidades do sujeito qual busca esse cuidado partindo de vulnerabilidades, e as consequências quais levam ao adoecimento mental como consequências ambientais e subjetivas como as apresentadas nessa categoria relatada no qual "Batman vs Superman: a origem da justiça" em que a trama traz um desastre com proporções ambientais quais afetam uma sociedade devido a uma grande batalha do Superman qual resultou em sentimentos e isso refletiu em Clark. De modo geral sempre existem motivações que levam o sujeito ao encontro do profissional, do qual se espera o acolhimento e cuidado em saúde mental com condutas éticas para que possa haver a relação terapêutica (Cardoso et al., 2016).

As relações humanas são base importante para constituição do aparelho social e essas relações partem de componentes como pensamento, vínculo e a interação como componentes da comunicação entre os indivíduos. Na lógica 
foucaultiana as relações humanas podem partir do princípio das relações de poder entre estes, então a partir desta lógica é entendido que os indivíduos podem se relacionar no contexto de relações assimétricas podendo utilizar esse empoderamento como aparelho para controle de quem e está vulnerável as suas decisões e condutas (Santos, 2016). Tomando assim de fato as relações de poder entre os indivíduos e na saúde mental as condutas dos profissionais que compõem uma equipe que presta o acolhimento e cuidado. O acolhimento, o vínculo, assim como o cuidado à pessoa em sofrimento mental dependem da relação estabelecida entre ambas as partes. No âmbito fictício mostra o quanto as relações de poder entre personagens que tem para uns com os outros, como exemplo, em Doutor Estranho, no qual Strange por ter a figura do grande cirurgião demonstra seu poder através dos seus conhecimentos a sua arrogância. Outra situação é falta de empatia da profissional para com Arthur de "Coringa", em "Vidro" uma profissional potencialmente biologicista não se preocupa em construir o cuidado e o tratamento levando em consideração aos sentimentos dos pacientes, fazendo juízo de poder dos sentimentos destes e desvalorizando assim a essência pessoal sendo antiética e se colocando numa posição de poder. Além da sociedade qual a médica busca ter o controle se colocando numa posição vertical e superior de subestimação da autonomia de outros atores sociais. Essas condutas refletem na postura ética e implicam na dificuldade no estabelecimento do vínculo e do cuidado em saúde mental.

\section{Conclusão}

Considerando as práticas em saúde com seus contextos, condutas legais e éticas, relações humanas e terapêuticas partindo de arcabouços teórico-filosóficos no que diz respeito às condutas profissionais perante o cuidado em saúde mental que é ofertado, foi observado na análise fílmica o comportamento dos personagens, suas interações com os demais e o ambiente, o que possibilitou a compreensão das diferenças entre atitudes dos que optam por uma corrente teórico-filosófica voltada para valores científicos e empíricos, centrados no modelo biomédico e biologicista.

Ao mesmo tempo também se observam as condutas em que o "humano" é valorizado por condutas que valorizam suas características singulares e sua individualidade no sentido da subjetividade humana, qual não tem o mesmo valor para pensadores racionalistas, já que o racionalismo super valoriza o questionamento e o teor científico em questionar verdades. Assim, essa análise parte dos princípios filosóficos do humanismo, que se teoriza pela valorização do que o sujeito é, e de como ele pensa sobre a sua existência, tendo proximidade dos valores centrados no holismo e no mágico-religioso, para o reconhecimento dos valores humanos como mostrado em comportamentos de personagens dos filmes.

Sendo que todos esses modelos em saúde são necessários para que aconteça o cuidado em saúde mental de acordo com seus princípios éticos, levando em consideração o fortalecimento na prática em saúde mental mais humana, sem deixar de partir de princípios científicos e éticos.

Portanto, é possível perceber, por meio desta análise fílmica as tramas baseadas em histórias de super heróis, a importância e a complexidade do processo de cuidar e de se relacionar (no contexto profissional-usuário de serviço) sem desviar dos aspectos éticos, que favorecem a promoção da saúde mental e dependem das condutas dos profissionais que atuam na nos serviços da atenção psicossocial.

Esta pesquisa pode ser considerada como propulsora na busca inicial de entender como se desenvolvem os princípios éticos na relação terapêutica entre profissionais e usuários, cabendo outras investigações que tragam maior compreensão às vivências da atenção em saúde na realidade dos serviços de saúde mental.

\section{Referências}

Almeida, J. M. C. (2019). Política de saúde mental no Brasil: o que está em jogo nas mudanças em curso. Cad. Saúde Pública, 35(11), 1-6.

Araújo, L. S. \& Bassalo, J. F. (2019). Modos de cuidado e saúde mental: apontamentos para uma prática psicossocial. Rev. NUFEN,.10(3), 137-153. 
Research, Society and Development, v. 11, n. 1, e45911125170, 2022 (CC BY 4.0) | ISSN 2525-3409 | DOI: http://dx.doi.org/10.33448/rsd-v11i1.25170

Barin, et al. (2020). Do trauma aos sintomas: um viés psicanalítico da franquia "It - A Coisa". Research Society and Development, 9(4), 1-14.

Batista, E. C. (2018). A Saúde Mental e o Cuidado à Pessoa em Sofrimento Psíquico na História da Loucura. Rev Enfermagem e Saúde Coletiva, 3(2), 1-15.

Bossato, H. R., et al. (2021). Protagonismo do usuário na assistência em saúde mental: uma pesquisa em base de dados. Barbarói, 58, 95-121.

Campos, D. B. Bezerra, I. C. \& Jorge, M. S. B. (2018). Tecnologias do cuidado em saúde mental: práticas e processos da Atenção Primária. Rev. Bras. Enferm., 71, 2228-2236.

Coelho, R. S. Velôso, T. M. G. \& Barros, S. M. M. (2017). Oficinas com Usuários de Saúde Mental: a Família como Tema de Reflexão. Psicol., Ciênc. Prof., 37(2), 489-499.

Paula, K. V. S. (2008). A questão da saúde mental e atenção psicossocial: considerações acerca do debate em torno de conceitos e direitos. Physis, 18(4), 836840.

Ferreira, M. A. (2020). Heróis de máscaras no sistema de saúde do brasil: a experiência da pandemia em sob pressão: plantão COVID. Revista GEMINIS 11(2), 81-98.

Ferreira, T. P. S., et al. (2019). A família no cuidado em saúde mental: desafios para a produção de vidas. Saúde debate, 43(121), 441-449.

Flick, U. (2009). Introdução à pesquisa qualitativa. Artmed.

Freitas, A. D. G. \& Leite, N. R. P. (2015) Linguagem fílmica: uma metáfora de comunicação para a análise dos discursos nas organizações. $R$. Adm., 50(1), 89-104.

Fuentes, J. C. (2017). Super heróis e outros mitos modernos: Aplicação pedagógica para reflexões filosóficas e formação ético-moral de jovens crianças. Revista do NESEF Filosofia e Ensino, 6(1), 71-82.

Gaino, L. V., et al. (2018). O conceito de saúde mental para profissionais de saúde: um estudo transversal e qualitativo. Rev. Eletrônica Saúde Mental Álcool Drog., 14(2), 108-116.

Leite, N. R. P. Nishimura, A. T. \& Leite, F. P. (2010). O estudo do construto amor em administração: ciência ou senso comum? Revista Reuna, $15(2)$, 59-81.

Machado, D. Q. et al. (2012). Estudos observacionais em linguagem fílmica. Editora CRV.

Machado, D. Q. Ipiranga, A. S. R. \& Oliveira, F. C. (2012). Os Princípios da Bioética em Práticas de Desenvolvimento Sustentável: um Estudo Observacional no filme "Avatar". Revista Brasileira de Pesquisa em Saúde, 14(3), 4-9.

Mendonça, S. M. (2019). Dignidade e autonomia do paciente com transtornos mentais. Rev. Bioét., 27(1), 46-52.

Munsterberg, H. (2003). A experiência do cinema: Antologia. Graal.

Penafria, M. (2009). Análise de Filmes - conceitos e metodologia(s). VI Congresso SOPCOM.

Peres, G. M., et al. (2018). Limites e desafios da rede de atenção psicossocial na perspectiva dos trabalhadores de saúde mental. Cadernos Brasileiros de Saúde Mental, 10(27), 34-52.

Ramos, A. C. Calais, S. L. \& Zotesso, M. C. (2019). Convivência do familiar cuidador junto a pessoa com transtorno mental. Contextos Clínic, 12(1), 281-302.

Reis, D. O., et al. Nem herói, nem vilão: elementos da prática médica na atenção básica em saúde. Ciênc. saúde colet., 23(8), 2651-2660.

Santos, P. R. (2016). A concepção de poder em Michel Foucault. Cadernos de Ciências Humanas, 16(28), $261-280$.

Scudeler, R. P. (2020). Ensaio a respeito da desistintucionalização por meio da análise de discurso de profissionais da saúde mental. Brazilian Journal of health Review, 3(3), 6122-6140.

Sousa, F. S. P. \& Jorge, M. S. B. (2019) O retorno da centralidade do hospital psiquiátrico: retrocessos recentes na política de saúde mental. Trab. educ. saúde, 17(1), 1-19.

Vanoye, F. \& Goliot-Lété, A (2008). Ensaio sobre a análise fílmica. Papirus Editora.

Viegas, S. I. R. (2008). Olhar e memória na percepção cinematográfica. Princípios: Revista de Filosofia, 15(24), 31-44. 